\title{
Burden of disease from Helicobacter pylori infection in western Canadian Arctic communities
}

Katharine Fagan-Garcia ${ }^{1 *} \mathbb{D}$, Janis Geary ${ }^{1}$, Hsiu-Ju Chang ${ }^{1}$, Laura McAlpine ${ }^{1}$, Emily Walker ${ }^{1,2}$, Amy Colquhoun², Sander Veldhuyzen van Zanten ${ }^{1}$, Safwat Girgis ${ }^{3}$, Billy Archie ${ }^{4}$, Brendan Hanley ${ }^{5}$, Andre Corriveau ${ }^{6}$, John Morse ${ }^{7}$, Rachel Munday ${ }^{8}$, Karen J. Goodman ${ }^{1,2}$ and CANHelp Working Group ${ }^{1}$

\begin{abstract}
Background: Indigenous communities across the circumpolar north have elevated H. pylori (Hp) prevalence and stomach cancer incidence. We aimed to describe the Hp-associated disease burden among western Canadian Arctic participants in community-driven projects that address concerns about health risks from $\mathrm{Hp}$ infection.

Methods: During 2008-2013, participants underwent Hp screening by urea breath test and gastroscopy with gastric biopsies. We estimated Hp prevalence and prevalence by Hp status of endoscopic and histopathologic diagnoses.

Results: Among 878 participants with Hp status data, Hp prevalence was: 62\% overall; 66\% in 740 Indigenous participants; $22 \%$ in 77 non-Indigenous participants (61 participants did not disclose ethnicity); $45 \%$ at 0-14 years old, 69\% at 15-34 years old, and 61\% at 35-96 years old. Among 309 participants examined endoscopically, visible mucosal lesions were more frequent in the stomach than the duodenum: the gastric to duodenal ratio was 2 for inflammation, 8 for erosions, and 3 for ulcers. Pathological examination in 308 participants with gastric biopsies revealed normal gastric mucosa in 1 of $224 \mathrm{Hp}$-positive participants and 77\% (65/84) of Hp-negative participants with sharp contrasts in the prevalence of abnormalities between $\mathrm{Hp}$-positive and $\mathrm{Hp}$-negative participants, respectively: moderate-severe active gastritis in 50 and 0\%; moderate-severe chronic gastritis in 91 and 1\%; atrophic gastritis in 43 and $0 \%$; intestinal metaplasia in 17 and 5\%.

Conclusions: The observed pattern of disease is consistent with increased risk of stomach cancer and reflects substantial inequity in the Hp-associated disease burden in western Arctic Canadian hamlets relative to most North American settings. This research adds to evidence that demonstrates the need for interventions aimed at reducing health risks from $\mathrm{Hp}$ infection in Indigenous Arctic communities.
\end{abstract}

Keywords: Helicobacter pylori, Arctic, Canada, Indigenous health, Prevalence, Gastritis, Gastric cancer, Peptic ulcer disease

\footnotetext{
* Correspondence: kfagan@ualberta.ca

${ }^{1}$ Department of Medicine, Division of Gastroenterology, University of Alberta,

Edmonton, Alberta, Canada

Full list of author information is available at the end of the article
}

(c) The Author(s). 2019 Open Access This article is distributed under the terms of the Creative Commons Attribution 4.0 International License (http://creativecommons.org/licenses/by/4.0/), which permits unrestricted use, distribution, and reproduction in any medium, provided you give appropriate credit to the original author(s) and the source, provide a link to the Creative Commons license, and indicate if changes were made. The Creative Commons Public Domain Dedication waiver (http://creativecommons.org/publicdomain/zero/1.0/) applies to the data made available in this article, unless otherwise stated. 


\section{Background}

Indigenous Peoples residing in northern Canada have an elevated prevalence of Helicobacter pylori $(\mathrm{Hp})$ infection relative to southern Canadians [1]. This bacterial infection can persist lifelong, causing chronic inflammation of the stomach lining; in a small proportion of cases (5-15\%), it causes peptic ulcer disease and, more rarely, stomach cancer [2]. Elevated $H p$ prevalence and stomach cancer rates have been observed in Indigenous communities across the circumpolar north relative to the average occurrence in the respective countries [1].

Systematic reviews of population-based studies report $\mathrm{Hp}$ prevalence estimates over 50\% across most of Africa, Asia and Latin America, with lower and declining prevalence in Australia-New Zealand, Europe and North America [3, 4]. While $H p$ prevalence varies substantially within countries by ethnicity and socioeconomic status, and many region-specific prevalence estimates come from unrepresentative samples [5], rough regional estimates range from $24 \%$ for AustraliaNew Zealand to $79 \%$ for Africa, with prevalence in Canada and the United States estimated at 36 and 38\%, respectively, in a 2017 systematic review [3]. Evidence from the late twentieth century showed $H p$ prevalence inversely associated with socioeconomic status within Europe and the United States [6, 7]. Because the infection typically is acquired in childhood, observed increases in $\mathrm{Hp}$ prevalence with age result from a cohort effect reflecting transmission levels within the first years after birth. Decreases in $H p$ prevalence observed in younger age groups in affluent countries suggests that transmission is decreasing in such countries, though it remains high in socioeconomically disadvantaged groups. In Canada, for example, the prevalence in pediatric patients residing in major urban centers was estimated in 2005 at just 5\%, while 56\% (92/163) of Wasagamack Cree children in northern Manitoba screened positive for $H p$ in 2002 [2, 8].

The Canadian North Helicobacter pylori (CANHelp) Working Group, a collaboration of academic scientists with Indigenous community leaders and their health care providers [9], conducts community-driven investigations focused on $H p$ infection in the Northwest Territories (NT) and Yukon (YT) [10-16]. Incorporating the perspective of those who bear the burden, results from these projects will be used to develop $\mathrm{Hp}$ control strategies that are cost-effective and culturally appropriate for Arctic Indigenous communities. Previous reports describe details of CANHelp projects and their community-driven approaches [10, $12-15,17]$. This paper describes the burden of disease from $\mathrm{Hp}$ infection among participants in CANHelp community projects.

\section{Methods}

\section{Research sought by communities}

The CANHelp research program arose from the confluence of three constituencies: residents of western Canadian Arctic communities worried about $\mathrm{Hp}$ infection and its link to stomach cancer; health care practitioners frustrated by poor effectiveness of available clinical management strategies for this frequently encountered infection; and public health officials seeking evidence to inform infection control strategies. In the early 2000s, NT health care officials sought input from University of Alberta researchers to respond to concerns voiced by community leaders. In 2006, a meeting between academic scientists and NT medical directors generated support for community-driven research aimed at describing the burden of disease from $\mathrm{Hp}$ infection in concerned communities. NT health care partners recommended the Hamlet of Aklavik for the initial project because Aklavik community leaders had advocated for research to reduce health risks from $\mathrm{Hp}$ infection. The Aklavik H. pylori Project launched in 2007. Word of its success generated interest in neighboring communities. Invited by community leaders, the research team launched community H. pylori Projects in Old Crow YT in 2010, Tuktoyaktuk NT in 2011 and Fort McPherson NT in 2012. Projects launched in 2016-2017 are not included in this report. The University of Alberta Health Research Ethics Board approved this research, and as required by law, we obtained annual research licenses in both NT and YT before collecting data.

\section{Participating communities}

Population estimates (from census nearest project launch) were 594 (2006) for Aklavik, 245 (2011) for Old Crow, 854 (2011) for Tuktoyaktuk, and 792 (2011) for Fort McPherson (Fig. 1) [18-21]. Most residents of participating communities identify as Indigenous: by census counts, in Aklavik, 92\% were Indigenous (mainly Inuvialuit (western Canadian Inuit) or Gwich'in (Athabaskan) First Nation); in Old Crow, 90\% were Vuntut Gwitchin (Athabaskan) First Nation; in Tuktoyaktuk, 92\% were Inuvialuit; and in Fort McPherson, 94\% were Indigenous (mainly Gwich'in) [18, 22]. Aklavik, $113 \mathrm{~km}$ south of the Arctic Coast, is accessible by air, ice road in winter and water in summer [23]. Old Crow, north of the Arctic Circle on the Porcupine River, is accessible only by air [24]. Tuktoyaktuk, on the Arctic Ocean coast, is accessible by air, highway year-round since November 2017 (before that by ice road in winter). Fort McPherson, on the Peel River, is accessible by highway year-round [23].

\section{Community-driven approach}

Each project launch required the formation of a planning committee of community residents; the process for recruiting committee members was devised by community 


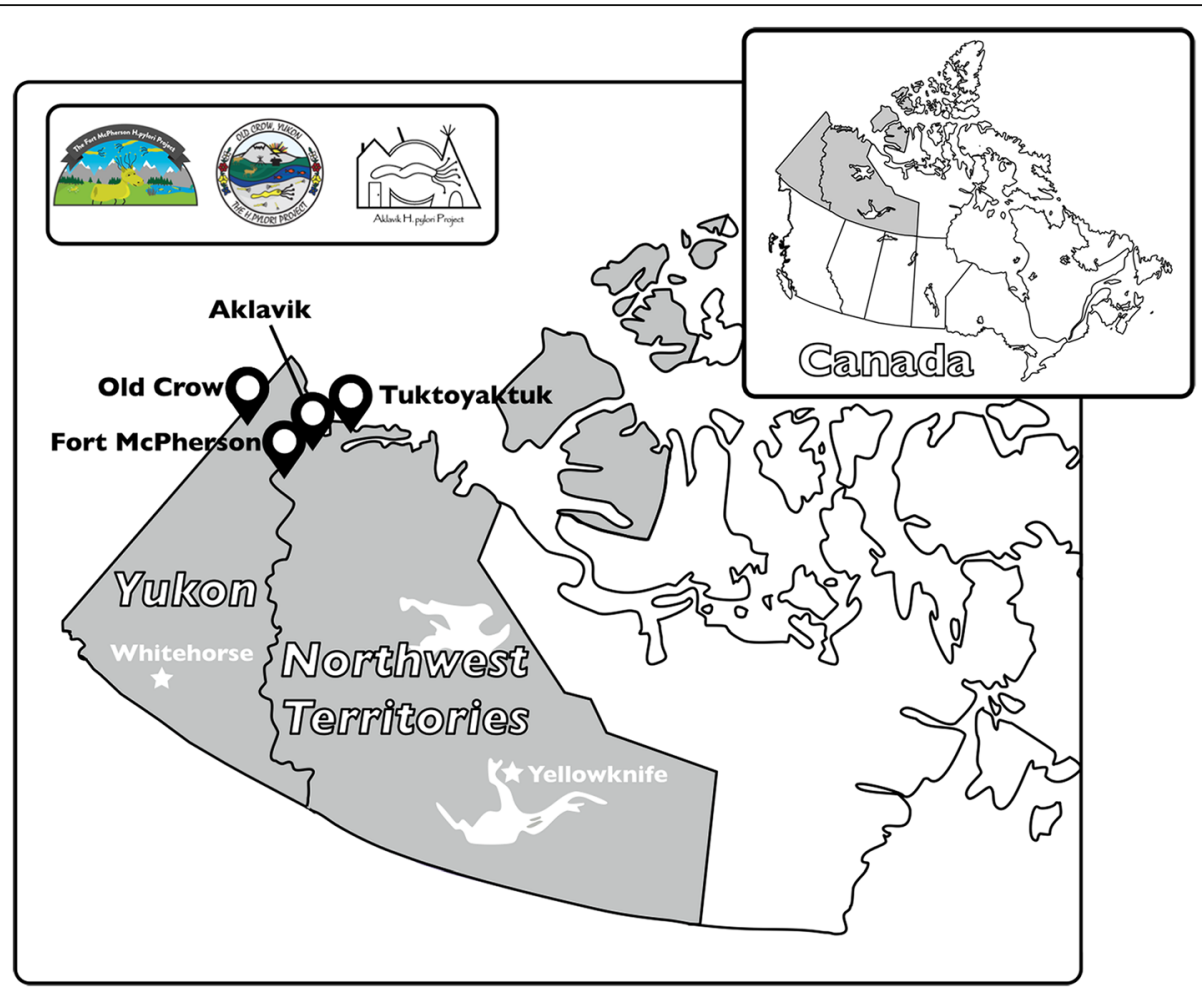

Fig. 1 Map of the western Canadian Arctic with partner community locations indicated. Inset shows logos of community projects that had contests to select a logo created by a local artist: Fort McPherson H. pylori Project (local artist - Johanna Edwards); Old Crow H. pylori Project (local artist - Mary Jane Moses); Aklavik H. pylori Project (local artist - Richard Papik). Map adapted from https://commons.wikimedia.org/wiki/File:Map_Canada_political-geo.png

partners. An exception was the Tuktoyaktuk project, launched at the request of the Inuvialuit Regional Corporation [25], with planning occurring in partnership with regional Inuvialuit leadership and a Tuktoyaktuk community health representative. Planning committees and other community partners provided input on design and implementation of all research activities to ensure they adhered to community priorities and cultural values. Planning committees and other community partners reviewed all research reports before they were made public.

\section{Study population and design}

Project recruitment activities in each community encouraged all residents to participate in baseline research activities: interviewer-administered questionnaires; $H p$ screening; and endoscopy with gastric biopsies for culture and pathological examination. After endoscopy activities concluded, randomized trials offered treatment to eliminate $H p$ infection to those testing positive. Participants gave written informed consent for overall project participation with additional consents for endoscopy and treatment. Participants $<17$ years old required written parental consent, with children deemed sufficiently mature providing written assent. Details can be found on the CANHelp Working Group website [9].

\section{Hp screening}

Beginning in January 2008, we offered screening for $H p$ infection using the 13C-urea breath test (UBT), the most accurate non-invasive test for detecting $\mathrm{Hp}$ infection in children and adults [26]; most well-designed validation studies estimate both sensitivity and specificity greater than 95\% against biopsy-based diagnosis [27], though it should be noted that biopsy-based diagnosis is not an optimal gold standard because tissue sampling can miss $\mathrm{Hp}$ in the stomach due to its patchy distribution and diagnostic accuracy also depends on tissue preparation techniques and observer expertise [26, 28, 29]. The UBT avoids these limitations, but its accuracy depends on optimal breath sample collection [30]. We used nondispersive isotope-selective infrared spectroscopy to measure the $13 \mathrm{C} / 12 \mathrm{C}$ ratio in breath samples collected before and after consumption of 13C-labeled urea [31, 32]; a positive result reflects presence of urease in the stomach, a highly specific marker for $H p$ infection. We asked participants to avoid acid-suppressing medications for $24 \mathrm{~h}$ before the test and to fast except for water for $4 \mathrm{~h}$ before the test. We obtained a baseline breath sample, asked participants to swallow 50-75 mg of 13C-labeled urea dissolved in citric acid, and collected a second breath sample $30 \mathrm{~min}$ after the urea solution was swallowed [17]. 


\section{Upper gastrointestinal endoscopy, histopathology, and microbiological culture}

Using ultra-slim Olympus gastroscopes, gastroenterologists performed unsedated upper gastrointestinal endoscopy for consenting participants, regardless of $H p$ status, in temporary endoscopy clinics organized in community health centers (2008 in Aklavik, 2012 in Old Crow, 2013 in Fort McPherson and at the Inuvik Regional Hospital for Tuktoyaktuk participants) [33]. The regional planning approach used for the Tuktoyaktuk project created logistic constraints that reduced time periods, relative to the other community projects, for recruiting participants and carrying out project activities; as a result, participation was not sufficient to warrant resources required for an endoscopy team to visit this community. Instead, we offered to pay travel expenses for Tuktoyaktuk residents willing to undergo endoscopy in Inuvik (a 2-h drive). Gastric biopsies collected during endoscopy were transported to the University of Alberta for histopathologic examination (2-3 from antrum, 2-3 from corpus) and tissue culture (1 from antrum, 1 from corpus) [14]. A single pathologist (SG) evaluated antral and corpus biopsies separately, grading $H p$ density, active and chronic gastritis, gastric atrophy, and other neoplastic lesions using the updated Sydney system [34]. We differentiate active gastritis, characterized by polymorphonuclear neutrophil infiltration occurring in the context of chronic inflammation, from chronic gastritis, characterized by the presence of mononuclear cells, chiefly lymphocytes, plasma cells and macrophages [34]. For culture, antral and corpus biopsies were pooled and mechanically homogenized; resulting suspensions were plated on brain heart infusion/yeast extract/5\% horse serum agar plates and incubated at $37^{\circ} \mathrm{C}$ in microaerophilic conditions. Cultures were checked for growth every $48 \mathrm{~h}$, for up to a month. Colonies consistent with $H p$ growth were subplated and expanded for generation of glycerol stocks. $H p$ classification was confirmed by urease, catalase, oxidase and $16 \mathrm{~S}$ ribosomal RNA PCR testing.

\section{Hp infection status}

We classified $H p$ infection status using all available results (UBT, histopathologic examination, and/or bacterial culture) for each participant. When results were discordant, we used an algorithm based on the probability that the status was negative or positive (for example, UBT positive + histopathology positive + culture negative was classified as positive; UBT negative + histopathology positive + culture negative was classified as negative). Among 254 participants with classifiable $H p$ status from 3 tests, 216 (85\%) were concordant on all 3 tests; among 53 participants with classifiable $H p$ status from just 2 tests, 47 (89\%) had concordant status. Of the 3 tests, UBT and histopathology agreed most frequently, for 263 of 272 (97\%) participants with results from both, while the results of culture diverged more frequently, agreeing with UBT for 218 of 254 (86\%) participants with both of these tests and with histopathology for 252 of 289 (87\%) participants with both of these tests. The more frequent discordance of culture is not surprising given the technical challenges inherent in tissue culture of $H p$ in the laboratory [30,35]. The high agreement of UBT and histopathology indicates comparable and excellent accuracy of these 2 diagnostic tests. Comparing UBT against histopathology as the gold standard, estimated sensitivity is $96 \%$ (95\% confidence interval (CI), 94-99\%) and estimated specificity is $97 \%$ (95\% CI, $94-100 \%)$. Conversely, comparing histopathology against UBT as the gold standard, estimated sensitivity is $99 \%$ (95\% CI, 98-100\%) and estimated specificity is $91 \%$ (95\% CI, 85-97\%).

\section{Statistical analysis}

The cross-sectional design is appropriate for investigations of the burden of disease from $H p$ in a community setting, given that the infection onset generally goes undetected, the infection often persists indefinitely without symptoms, and gastric disease caused by the infection is often asymptomatic. Screening for prevalent cases is, therefore, the starting point for describing the occurrence of $\mathrm{Hp}$ infection and related disease in a population. To describe the burden of infection in participating communities, we present the estimated prevalence of $H p$ infection and 95\% confidence intervals by age, sex, ethnicity and community. To describe the burden of gastric disease related to $H p$ infection and demonstrate relatedness of specific conditions to $H p$ infection, we present the estimated prevalence of endoscopic diagnoses (esophagitis/esophageal erosions, Barrett's esophagus, gastritis, gastric erosions, gastric ulcer, duodenitis, duodenal erosions, duodenal ulcer) and histopathologic diagnoses (active gastritis, chronic gastritis, gastric atrophy, benign MALT hyperplasia or lymphoid aggregates, lymphoepithelial lesions, intestinal metaplasia, dysplasia, carcinoma) and $95 \% \mathrm{CIs}$ by $\mathrm{Hp}$ status. In analyses of endoscopy or histopathology results, we excluded the small number of participants who underwent treatment to eliminate $H p$ after the screening UBT and before endoscopy.

\section{Results \\ Participation and data availability}

The four community projects enrolled 934 participants, representing $38 \%$ of the combined populations of these communities (Table 1). The first two community projects had the highest participation, with 64 and $85 \%$ of residents of Aklavik and Old Crow, respectively. $H p$ status was available for 878 (94\%) of the 934 participants. Table 2 shows participation in UBT screening and endoscopy by community, with UBT results available for 90\% (841/934) and histopathology results available for 33\% (308/934). Due to the logistic challenges, only 5 Tuktoyaktuk residents had 
Table 1 Participation in CANHelp projects and availability of Hp status data, western Arctic Canadian communities, 2007-2013

\begin{tabular}{|c|c|c|c|c|c|c|}
\hline \multirow[t]{2}{*}{ Community } & \multirow{2}{*}{$\begin{array}{l}\text { Launch } \\
\text { Year }\end{array}$} & \multirow{2}{*}{$\begin{array}{l}\text { Census- } \\
\text { estimated }^{\text {a }} \\
\text { Population }\end{array}$} & \multicolumn{2}{|c|}{ Enrolled Participants (signed consent) } & \multicolumn{2}{|c|}{ Participants with Data on H. pylori Status } \\
\hline & & & $n$ & $\%$ of Census & $n$ & $\%$ of Participants \\
\hline Aklavik & 2007 & 594 & 383 & 64 & 352 & 92 \\
\hline Old Crow & 2010 & 245 & 208 & 85 & 200 & 96 \\
\hline Tuktoyaktuk & 2011 & 854 & 107 & 13 & 102 & 95 \\
\hline Fort McPherson & 2012 & 792 & 236 & 30 & 224 & 95 \\
\hline Total & & 2485 & 934 & 38 & 878 & 94 \\
\hline
\end{tabular}

${ }^{\mathrm{a}}$ From 2006 census for Aklavik [18]; from 2011 census for other communities [19-21]

eligible histopathology results: each fell in a different age group; 4 were women; 5 were Indigenous ( 4 were Inuvialuit, the dominant ethnicity in Tuktoyaktuk); and 4 were $\mathrm{Hp}$-positive with a distribution of endoscopic and histopathologic outcomes reflective of the larger study population.

Table 3 shows the distribution of age, sex, community and ethnicity in all 934 participants and in two study population subsets: the 878 with $\mathrm{Hp}$ status and the 308 with histopathology results. Aside from the exclusion of young children from endoscopy, the age distribution of the two subpopulations approximates that of the total study population. The sex distribution is similar across study population subsets, with women accounting for $54-56 \%$ of each. The proportion identifying as Indigenous is $90-92 \%$ across study subpopulations. The representation of communities is nearly identical in the total study population and among those with $H p$ status, but among those with histopathology results Aklavik is overrepresented due to a much higher proportion of participants undergoing endoscopy in the first project, and Tuktoyaktuk is underrepresented due to only 13 participants traveling to Inuvik for endoscopy. Just 56 (6\%) participants lacked data on $H p$ status; these participants were disproportionately younger and male.

\section{Hp prevalence}

Among 878 participants with $H p$ status, $62 \%$ were $H p$ positive (Table 4). The prevalence was $45 \%$ (95\% CI, 36$55 \%)$ in children under $15,69 \%(95 \% \mathrm{CI}, 63-74 \%)$ in the $15-34$-year age group, and $61 \%(95 \% \mathrm{CI}, 57-66 \%)$ in the 35-96-year age group. The prevalence was somewhat higher in men $(65 \%$; $95 \% \mathrm{CI}, 60-70 \%)$ than women (59\%; 95\% CI, 55-63\%). Across communities, the prevalence ranged from $57 \%$ in Tuktoyaktuk to $68 \%$ in Old Crow. The largest variation in prevalence was by ethnicity, with non-Indigenous participants having a much lower prevalence $(22 \%$; $95 \%$ CI, $13-31 \%)$ than Indigenous participants (66\%; 95\% CI, 62-69\%).

\section{Endoscopic assessment}

Table 5 shows the prevalence of abnormalities observed during endoscopy by $\mathrm{Hp}$ status. Of note, $79 \%$ of $\mathrm{Hp}$-positive participants had gastric mucosa that appeared normal. Visible esophagitis and Barrett's esophagus were more prevalent in $H p$-negative participants (11 and 7\%, respectively) than $H p$-positive participants ( 8 and $4 \%$, respectively) . Paradoxically, the prevalence of visible gastritis, gastric erosions and gastric ulcers was not markedly different in groups defined by $H p$ status: $12-15 \%$ had visible gastritis, $8-11 \%$ had gastric erosions, and $3-4 \%$ had gastric ulcers. The prevalence of visible duodenal lesions was lower: duodenal lesions were observed in $9 \%$ of $H p$-positive participants and $4 \%$ of $\mathrm{Hp}$-negative participants. No $\mathrm{Hp}$-negative participants had visible duodenal erosions or ulcers and $4 \%$ had duodenitis, while $1 \%$ of $\mathrm{Hp}$-positive participants had duodenal erosions, $1 \%$ had duodenal ulcers, and $7 \%$ had duodenitis. In all 308 participants with complete endoscopic assessment, the gastric to duodenal ratio was 2 for inflammation, 8 for erosions, and 3 for ulcers. In 271 Indigenous participants, the gastric to duodenal ratio was 2 for inflammation, 6 for erosions, and 8 for ulcers.

Table 2 Participation in CANHelp project diagnostic testing and availability of results, western Arctic Canadian communities, 20082013

\begin{tabular}{|c|c|c|c|c|c|c|c|c|c|}
\hline \multirow[t]{3}{*}{ Community } & \multirow{3}{*}{$\begin{array}{l}\text { Enrolled Participants } \\
\text { n }\end{array}$} & \multicolumn{4}{|l|}{ UBT } & \multicolumn{4}{|c|}{ Endoscopy } \\
\hline & & \multicolumn{2}{|c|}{ Completed } & \multicolumn{2}{|c|}{ Classifiable Result } & \multicolumn{2}{|c|}{ Completed } & \multicolumn{2}{|c|}{ Histopathology Results } \\
\hline & & $\bar{n}$ & $\%$ & $\bar{n}$ & $\%$ & $\bar{n}$ & $\%$ & $\bar{n}$ & $\%$ \\
\hline Aklavik & 383 & 334 & 87 & 333 & 87 & 196 & 51 & 194 & 51 \\
\hline Old Crow & 208 & 199 & 96 & 192 & 92 & 59 & 28 & 59 & 28 \\
\hline Tuktoyaktuk & 107 & 104 & 97 & 102 & 95 & 5 & 5 & 5 & 5 \\
\hline Fort McPherson & 236 & 228 & 97 & 214 & 91 & 50 & 21 & 50 & 21 \\
\hline Total & 934 & 865 & 93 & 841 & 90 & 310 & 33 & 308 & 33 \\
\hline
\end{tabular}


Table 3 Characteristics of CANHelp project participants by data availability, 2007-2013

\begin{tabular}{|c|c|c|c|c|c|c|c|c|}
\hline & \multicolumn{2}{|c|}{$\begin{array}{l}\text { All } 934 \\
\text { Participants }\end{array}$} & \multicolumn{2}{|c|}{$\begin{array}{l}878 \text { Participants } \\
\text { with Hp Status }\end{array}$} & \multicolumn{2}{|c|}{$\begin{array}{l}308 \text { Participants with } \\
\text { Histopathology }\end{array}$} & \multicolumn{2}{|c|}{$\begin{array}{l}56 \text { Participants } \\
\text { without Hp Status }\end{array}$} \\
\hline & $n$ & $\%^{a}$ & $n$ & $\%^{a}$ & $n$ & $\%^{a}$ & $\mathrm{n}$ & $\%^{a}$ \\
\hline$\overline{\text { Age }}$ & & & & & & & & $x^{2}-p$-value ${ }^{b}: 0.006$ \\
\hline $0-9.75$ & 76 & 8 & 65 & 7 & 0 & 0 & 11 & 20 \\
\hline $9.8-14^{c}$ & 45 & 5 & 41 & 5 & 8 & 3 & 4 & 7 \\
\hline $15-24$ & 136 & 15 & 124 & 14 & 46 & 15 & 12 & 22 \\
\hline $25-34$ & 142 & 15 & 135 & 15 & 45 & 15 & 7 & 13 \\
\hline $35-44$ & 121 & 13 & 118 & 13 & 41 & 13 & 3 & 6 \\
\hline $45-54$ & 170 & 18 & 165 & 19 & 75 & 24 & 5 & 9 \\
\hline $55-64$ & 133 & 14 & 128 & 15 & 57 & 18 & 5 & 9 \\
\hline $65-96$ & 109 & 12 & 102 & 12 & 36 & 12 & 7 & 13 \\
\hline missing & 2 & & 0 & & 0 & & 2 & \\
\hline Sex & & & & & & & & $x^{2}-p$-value $e^{b}: 0.09$ \\
\hline Male & 430 & 46 & 398 & 45 & 137 & 44 & 32 & 57 \\
\hline Female & 504 & 54 & 480 & 55 & 171 & 56 & 24 & 43 \\
\hline missing & 0 & & 0 & & 0 & & 0 & \\
\hline Community & & & & & & & & $x^{2}-p$-value $e^{b}: 0.15$ \\
\hline Aklavik & 383 & 41 & 352 & 40 & 194 & 63 & 31 & 55 \\
\hline Old Crow & 208 & 22 & 200 & 23 & 59 & 19 & 8 & 14 \\
\hline Tuktoyaktuk & 107 & 11 & 102 & 12 & 5 & 2 & 5 & 9 \\
\hline Fort McPherson & 236 & 25 & 224 & 26 & 50 & 16 & 12 & 21 \\
\hline missing & 0 & & 0 & & 0 & & 0 & \\
\hline Ethnicity & & & & & & & & $x^{2}-p$-value $e^{b}: 0.41$ \\
\hline Non-Indigenous & 82 & 10 & 77 & 9 & 22 & 8 & 5 & 13 \\
\hline Indigenous & 775 & 90 & 740 & 91 & 271 & 92 & 35 & 88 \\
\hline Inuvialuit (Inuit) & 305 & 36 & 289 & 35 & 121 & 41 & 16 & 40 \\
\hline Gwich'in (First Nations) & 424 & 49 & 405 & 50 & 133 & 45 & 19 & 48 \\
\hline Other/mixed ${ }^{d}$ & 46 & 5 & 46 & 6 & 17 & 6 & 0 & 0 \\
\hline missing & 77 & & 61 & & 15 & & 16 & \\
\hline
\end{tabular}

Hp H. pylori

${ }^{a} \%$ of column total minus missing; distributions do not all sum $100 \%$ due to rounding

${ }^{b}$ For the comparison of the distribution in participant groups with and without $\mathrm{Hp}$ status

'The 9.8-14 category includes two participants < 10: one who was 9 years and 10 months at the time of UBT and 9 years and 11 months at endoscopy, and one who was 9 years and 11 months at the time of UBT with no endoscopy

${ }^{d}$ Includes: Métis; mixed Indigenous ethnicities; unspecified Indigenous ethnicity; Indigenous mixed with non-Indigenous ethnicities

We examined whether the similar frequencies of endoscopically observed gastric abnormalities in groups defined by $H p$ status were due to previous $H p$ infection eliminated by antimicrobial therapy among $H p$-negatives or recent use of proton pump inhibitors (PPI) or H2receptor antagonists (H2RA), which decrease the density of $H p$ organisms, thereby reducing the sensitivity of diagnostic tests. In the $84 \mathrm{Hp}$-negative participants with treatment history data, $30(36 \%)$ had previous treatment; the proportion classified as having normal gastric mucosa was $80 \%$ among those treated previously and $77 \%$ among those not treated previously (for duodenal mucosa, these proportions were 97 and 96\%, respectively).
Among 302 participants with medication data, recent PPI/H2RA use was reported by $11 \%$ of $\mathrm{Hp}$-positives and $27 \%$ of $\mathrm{Hp}$-negatives. To assess the hypothesis that $\mathrm{Hp}$ negatives with abnormal gastric mucosa were false negatives due to medication use, we compared the proportion classified as having normal gastric mucosa by PPI/ H2RA use: in $85 \mathrm{Hp}$-negatives, $74 \%$ among users and $79 \%$ among non-users (for duodenal mucosa, 91 and 98\%, respectively); in $218 \mathrm{Hp}$-positives, 68\% among users and $80 \%$ among non-users (for duodenal mucosa, 96 and $91 \%$, respectively). Thus, this paradox does not appear to be due to previously treated $H p$ infection or medication use among current $H p$-negatives. 
Table $4 \mathrm{Hp}$ prevalence by demographic characteristics, 878 CANHelp project participants with Hp status, 2008-2013

\begin{tabular}{|c|c|c|c|c|}
\hline & \multirow[t]{2}{*}{$\mathrm{n}$} & \multicolumn{3}{|c|}{ Hp Prevalence } \\
\hline & & $\mathrm{n}$ & $\%$ & $95 \% \mathrm{Cl}$ \\
\hline Total & 878 & 541 & 62 & 58,65 \\
\hline \multicolumn{5}{|l|}{ Age } \\
\hline $0-9.75$ & 65 & 30 & 46 & 34,58 \\
\hline $9.8-14^{\mathrm{a}}$ & 41 & 18 & 44 & 29,59 \\
\hline $15-24$ & 124 & 85 & 69 & 60,77 \\
\hline $25-34$ & 135 & 93 & 69 & 61,77 \\
\hline $35-44$ & 118 & 70 & 59 & 50,68 \\
\hline $45-54$ & 165 & 103 & 62 & 55,70 \\
\hline $55-64$ & 128 & 78 & 61 & 52,69 \\
\hline $65-96$ & 102 & 64 & 63 & 53,72 \\
\hline \multicolumn{5}{|l|}{ Sex } \\
\hline Male & 398 & 258 & 65 & 60,70 \\
\hline Female & 480 & 283 & 59 & 55,63 \\
\hline \multicolumn{5}{|l|}{ Community } \\
\hline Aklavik & 352 & 213 & 61 & 55,66 \\
\hline Old Crow & 200 & 136 & 68 & 62,74 \\
\hline Tuktoyaktuk & 102 & 58 & 57 & 47,66 \\
\hline Fort McPherson & 224 & 134 & 60 & 53,66 \\
\hline \multicolumn{5}{|l|}{ Ethnicity } \\
\hline Non-Indigenous & 77 & 17 & 22 & 13,31 \\
\hline Indigenous & 740 & 486 & 66 & 62,69 \\
\hline Inuvialuit (Inuit) & 289 & 193 & 67 & 61,72 \\
\hline Gwich'in (First Nations) & 405 & 260 & 64 & 60,69 \\
\hline Other/mixed ${ }^{b}$ & 46 & 33 & 72 & 59,85 \\
\hline missing & 61 & & & \\
\hline
\end{tabular}

$\mathrm{Hp} \mathrm{H}$. pylori, $\mathrm{Cl}$ binomial Wald confidence interval

${ }^{\text {a The }}$ 9.8-14 category includes two participants <10: one who was 9 years and 10 months at the time of UBT and 9 years and 11 months at endoscopy, and one who was 9 years and 11 months at the time of UBT with no endoscopy ${ }^{\mathrm{b}}$ Category includes: Métis; mixed Indigenous ethnicities; unspecified

Indigenous ethnicity; mixed Indigenous and non-Indigenous ethnicities

\section{Histopathologic assessment}

Groups defined by $H p$ status had strikingly different frequencies of abnormal histopathology (Table 6). The proportion with normal gastric mucosa was $77 \%$ among $\mathrm{Hp}$ negative participants evaluated and just 1 of $224 \mathrm{Hp}$-positive participants evaluated. Compared to $H p$-negative participants, $\mathrm{Hp}$-positive participants not only had a much higher prevalence of histologic abnormalities, but they also had a much higher severity gradient, although the frequency of intestinal metaplasia was low in both groups and the difference between groups less striking. Of the 4 $\mathrm{Hp}$-negatives with intestinal metaplasia, 2 had a record of previous treatment to eliminate $H p$.

The results show good statistical precision for describing the severity distributions of the histopathological outcomes and differentiating these distributions in groups defined by $\mathrm{Hp}$ status. The study population yields even greater precision for differentiating the presence or absence of these outcomes: active gastritis occurred in 96\% (95\% CI, 92-98\%) of positives and 2\% (95\% CI, 0$8 \%$ ) of negatives; chronic gastritis occurred in $99 \%$ (95\% CI, $98-100 \%)$ of positives and $13 \%$ (95\% CI, 6-20\%) of negatives; gastric atrophy occurred in $43 \%$ (95\% CI, 36$49 \%$ ) of positives and $0 \%(95 \% \mathrm{CI}, 0-4 \%)$ of negatives; intestinal metaplasia occurred in 17\% (95\% CI, 12-22\%) of positives and $5 \%(95 \% \mathrm{CI}, 1-12 \%)$ of negatives; MALT hyperplasia or lymphoid aggregates occurred in $74 \%$ (95\% CI, $69-80 \%$ ) of positives and $12 \%$ (95\% CI, 5-19\%) of negatives; lymphoepithelial lesions occurred in 3\% (95\% CI, $1-6 \%)$ of positives and $0 \%(95 \% \mathrm{CI}, 0-4 \%)$ of negatives. Thus, each of these histopathological outcomes was strongly associated with prevalent $\mathrm{Hp}$ infection in this population.

\section{Discussion}

This analysis shows a high $\mathrm{Hp}$-associated disease burden in four western Canadian Arctic hamlets, with an estimated $H p$ prevalence of $66 \%$ among Indigenous residents and $22 \%$ among non-Indigenous residents. Among participants examined endoscopically, visible inflammation, erosions and ulcers were more frequent in the stomach relative to the duodenum. Pathological examination revealed a low prevalence of mild abnormalities among $H p$-negative participants; in contrast, $H p$-positive participants had a high prevalence of moderate-severe active and chronic gastritis; the prevalence of atrophic gastritis was $43 \%$ among $\mathrm{Hp}$ positive participants and 0 among $\mathrm{Hp}$-negative participants, while the prevalence of intestinal metaplasia was $17 \%$ among $\mathrm{Hp}$-positive participants and 5\% among $\mathrm{Hp}$-negative participants.

The pattern of disease observed in this population is consistent with increased risk of stomach cancer [36]. While no cases of dysplasia or carcinoma were detected, none would be expected due to small numbers. During 2008-2016, 3 of the 726 NT participants in this analysis had gastric cancer diagnosed and reported to the NT Cancer Registry (NT Department of Health and Human Services staff, personal communication, July 2018). While small community sizes preclude meaningful estimates of the frequency of gastric dysplasia or carcinoma, the combined community study population yields good statistical precision for estimating the prevalence and severity distributions of less advanced $H p$-associated pathological outcomes. The elevated ratio of gastric to duodenal lesions is the inverse of the pattern observed in populations where the risk of stomach cancer is low and $H p$ infection frequently leads to duodenal ulcers [36-38]. The more frequent occurrence of gastric ulcer relative to duodenal ulcer has been observed in other 
Table 5 Prevalence of endoscopic abnormalities by Hp status, 309 CANHelp project participants with endoscopy data, 2008-2013

\begin{tabular}{|c|c|c|c|c|c|c|}
\hline & \multicolumn{3}{|c|}{ Hp positive } & \multicolumn{3}{|c|}{ Hp negative } \\
\hline & \multicolumn{3}{|c|}{$(n=224)$} & \multicolumn{3}{|c|}{$(n=85)$} \\
\hline & $\mathrm{n}$ & $\%$ & $95 \% \mathrm{Cl}$ & $\mathrm{n}$ & $\%$ & $95 \% \mathrm{Cl}$ \\
\hline Normal gastric mucosa ${ }^{a}$ & 177 & 79 & 74,84 & 65 & 77 & 68,86 \\
\hline Normal duodenal mucosa & 204 & 91 & 87,95 & 82 & 96 & 93,100 \\
\hline Normal gastric and duodenal mucosa ${ }^{a}$ & 162 & 72 & 66,78 & 62 & 74 & 64,83 \\
\hline Esophagitis/esophageal erosions & 19 & 8 & 5,12 & 9 & 11 & 5,19 \\
\hline Barrett's esophagus & 8 & 4 & 2,7 & 6 & 7 & 3,15 \\
\hline Gastric inflammation, erosions, or ulcers ${ }^{a}$ & 46 & 21 & 15,26 & 17 & 20 & 12,29 \\
\hline Gastritis $^{a}$ & 33 & 15 & 10,19 & 10 & 12 & 5,19 \\
\hline Gastric erosions $^{a}$ & 17 & 8 & 4,11 & 9 & 11 & 5,19 \\
\hline Gastric ulcer $^{\mathrm{a}}$ & 6 & 3 & 1,6 & 3 & 4 & 1,10 \\
\hline Duodenal inflammation, erosions, or ulcers & 20 & 9 & 5,13 & 3 & 4 & 1,10 \\
\hline Duodenitis & 16 & 7 & 4,11 & 3 & 4 & 1,10 \\
\hline Duodenal erosions & 3 & 1 & 0,4 & 0 & 0 & 0,4 \\
\hline Duodenal ulcer & 3 & 1 & 0,4 & 0 & 0 & 0,4 \\
\hline
\end{tabular}

$\mathrm{Hp} \mathrm{H}$. pylori, $\mathrm{Cl}$ binomial Wald confidence interval (binomial exact $\mathrm{Cl}$ for numerators < 10; one-sided binomial exact $97.5 \% \mathrm{Cl}$ for numerators of 0 )

${ }^{a}$ One $\mathrm{Hp}$-negative participant was missing gastric mucosa assessment, so the denominator is 84 for gastric abnormalities among $\mathrm{Hp}$-negatives

populations at increased risk of stomach cancer [37, 38]. In addition, chronic gastritis and gastric atrophy are initial stages in Correa's widely accepted model of gastric carcinogenesis [39]; thus, the high prevalence of these conditions are further indications of increased stomach cancer risk in participating communities.

The estimated prevalence of endoscopically and histopathologically diagnosed gastric disease associated with $\mathrm{Hp}$ infection in CANHelp community project participants is a rare resource given that very few communitybased studies have assessed geographically-defined communities for these diagnoses. A recent clinic-based study of 432 Alaska Natives undergoing endoscopic assessment for digestive symptoms estimated similarly high prevalence of stomach pathology in $\mathrm{Hp}$-positive participants [40]; prevalence estimates for Alaska Native patients and Indigenous CANHelp project participants, respectively, were 78 and $97 \%$ for active gastritis, 98 and 99\% for chronic gastritis, and 13 and 17\% for intestinal metaplasia [40]. Estimated prevalence of stomach pathology in $\mathrm{Hp}$-negative participants was higher in Alaska Native patients than CANHelp project participants, respectively: 18 and 3\% for active gastritis; 69 and 14\% for chronic gastritis; and 10 and $6 \%$ for intestinal metaplasia [40]. The Alaska Native patients had much higher prevalence of endoscopically detectable gastric disease than the CANHelp project participants (for example, $85 \%$ of Alaska Native patients had an endoscopic diagnosis of gastritis, in contrast to $14 \%$ of CANHelp project participants), which is likely to be due, at least in part, to the clinic-based study design that recruited symptomatic patients who would have more severe disease on average than a community-based population [40]. In addition, the ratio of gastric to duodenal ulcers in the Alaska Native participants was nearly 5 (33:7) [40].

The pattern of gastric disease observed among $\mathrm{Hp}$ positive CANHelp community project participants contrasts sharply with the pattern we reported previously for $\mathrm{Hp}$-positive patients with gastric biopsies evaluated at the University of Alberta Hospital in Edmonton, Alberta (metro area 2016 census population $=1,321,426$ ) between April 2010 and March 2011 [14, 41]. In this patient population $(H p$ prevalence $=14 \%$ in $\sim 3000$ patients assessed), of roughly $400 \mathrm{Hp}$-positive patients evaluated, $11 \%$ had active gastritis, $40 \%$ had mild chronic gastritis, $55 \%$ had moderate chronic gastritis, $5 \%$ had severe chronic gastritis, and just $2 \%$ had gastric atrophy. Thus, compared to an urban southwestern Canadian population of patients of predominantly European ancestry [41] evaluated for digestive complaints, the community-based study population of residents of predominantly Indigenous western Canadian Arctic hamlets had a prevalence of $\mathrm{Hp}$ infection over 4 times higher along with a notably more severe pattern of gastric mucosal injury among those infected. This contrast reveals substantial inequity in the disease burden associated with $H p$ infection in western Arctic Canadian hamlets relative to a North American metropolis.

In addition to the small study size for estimating rare outcomes, another limitation of this investigation is the possibility that the participants did not accurately represent the participating communities. Within the constraints of available resources, every effort was made to include all residents of participating communities. If 
Table 6 Severity of gastric pathology by Hp status, 308 CANHelp project participants with histopathology data, 20082013

\begin{tabular}{|c|c|c|c|c|c|c|}
\hline \multirow[t]{2}{*}{ Pathology } & \multicolumn{3}{|c|}{ Hp positive $(n=224)$} & \multicolumn{2}{|c|}{ Hp negative $(n=84)$} & \multirow[b]{2}{*}{$x^{2}-p$-value } \\
\hline & $\mathrm{n}$ & $\%^{\mathrm{a}}$ & $95 \% \mathrm{Cl}$ & $\%^{a}$ & $95 \% \mathrm{Cl}$ & \\
\hline
\end{tabular}

Normal histopathology

\begin{tabular}{|c|c|c|c|c|c|c|c|}
\hline No & 223 & 99.6 & 99,100 & 19 & 23 & 14,32 & 0.000 \\
\hline Yes & 1 & 0.4 & 0,2 & 65 & 77 & 68,86 & \\
\hline \multicolumn{8}{|c|}{ Active gastritis $^{c}$} \\
\hline None & 7 & 3 & 1,6 & 82 & 98 & 94,100 & \multirow[t]{4}{*}{0.000} \\
\hline Mild & 102 & 46 & 39,52 & 2 & 2 & 0,8 & \\
\hline Moderate & 81 & 36 & 30,42 & 0 & 0 & 0,4 & \\
\hline Severe & 32 & 14 & 10,19 & 0 & 0 & 0,4 & \\
\hline \multicolumn{8}{|c|}{ Chronic gastritis } \\
\hline None & 2 & 1 & 0,2 & 73 & 87 & 80,94 & \multirow[t]{4}{*}{0.000} \\
\hline Mild & 17 & 8 & 4,11 & 10 & 12 & 5,19 & \\
\hline Moderate & 99 & 44 & 38,51 & 1 & 1 & 0,6 & \\
\hline Severe & 106 & 47 & 41,54 & 0 & 0 & 0,4 & \\
\hline \multicolumn{8}{|l|}{ Atrophy } \\
\hline None & 128 & 57 & 51,64 & 84 & 100 & 96,100 & \multirow[t]{4}{*}{0.000} \\
\hline Mild & 68 & 30 & 24,36 & 0 & 0 & 0,4 & \\
\hline Moderate & 23 & 10 & 6,14 & 0 & 0 & 0,4 & \\
\hline Severe & 5 & 2 & 1,5 & 0 & 0 & 0,4 & \\
\hline \multicolumn{8}{|c|}{ Intestinal metaplasia } \\
\hline None & 185 & 83 & 78,88 & 80 & 95 & 91,100 & \multirow[t]{4}{*}{0.002} \\
\hline Mild & 23 & 10 & 6,14 & 4 & 5 & 1,12 & \\
\hline Moderate & 13 & 6 & 3,9 & 0 & 0 & 0,4 & \\
\hline Severe & 3 & 1 & 0,4 & 0 & 0 & 0,4 & \\
\hline \multicolumn{8}{|c|}{ MALT hyperplasia $^{d}(n=114 ; 96 \mathrm{HP}+)$} \\
\hline None & 3 & 3 & 1,9 & 13 & 72 & 52,93 & \multirow[t]{4}{*}{0.000} \\
\hline Mild & 34 & 35 & 26,45 & 5 & 28 & 10,53 & \\
\hline Moderate & 45 & 47 & 37,57 & 0 & 0 & 0,19 & \\
\hline Severe & 14 & 15 & 8,22 & 0 & 0 & 0,19 & \\
\hline \multicolumn{8}{|c|}{ Lymphoid aggregates $^{d}(n=194 ; 128 \mathrm{HP}+)$} \\
\hline Present & 74 & 58 & 49,66 & 5 & 8 & 3,17 & 0.000 \\
\hline \multicolumn{8}{|c|}{ Lymphoepithelial lesions } \\
\hline Present & 7 & 3 & 1,6 & 0 & 0 & 0,4 & 0.101 \\
\hline \multicolumn{8}{|c|}{ Dysplasia or Carcinoma } \\
\hline Present & 0 & 0 & 0,2 & 0 & 0 & 0,4 & $\mathrm{n} / \mathrm{a}$ \\
\hline $\begin{array}{l}\mathrm{Hp} \mathrm{H} \text {. pylori, } \\
\text { numerators < } \\
\text { a'Distributions } \\
\text { bexcludes MAL } \\
\text { reactive gastro } \\
\mathrm{c}^{2} \mathrm{H} \text {. pylori-po } \\
{ }^{\mathrm{d}} \text { In 2008, pres } \\
\text { grading MALT } \\
\text { noting presen } \\
\text { eFrom score te }\end{array}$ & $\begin{array}{l}\text { do not } \\
\text { Thype } \\
\text { pathy } \\
\text { itive pa } \\
\text { nce/ab }\end{array}$ & $\begin{array}{l}\text { all sum } \\
\text { rplasia c c } \\
\text { articipan } \\
\text { sence } \\
\text { lasia; af } \\
\text { nce of } \\
\text { rend of }\end{array}$ & $\begin{array}{l}\text { d confidenc } \\
\text { inomial ex } \\
100 \% \text { due } \\
\text { or lymphoic } \\
\text { ts lack clas } \\
\text { f lymphoid } \\
\text { ter } 2008, M \\
\text { ymphoid a } \\
\text { odds }\end{array}$ & to rou & ding & $\begin{array}{l}\text { ludes } \\
\text { ive gastr } \\
\text { noted }\end{array}$ & $\begin{array}{l}\text { is } \\
\text { ithout } \\
\text { ed instead of }\end{array}$ \\
\hline
\end{tabular}

those who did not participate included a greater proportion of community members who were less eager to engage in health care, then we would likely have underestimated the prevalence of $\mathrm{Hp}$ infection and associated pathology. There was also potential for misclassification of $\mathrm{Hp}$ status and histopathology outcomes given imperfect diagnostic methods. The accuracy estimates generated by our data for classifying $\mathrm{Hp}$ status, however, suggest that our $\mathrm{Hp}$ prevalence estimates are roughly accurate for the study population. Also, the comparison of our histopathology results to those of $\mathrm{Hp}$-positive patients evaluated by the University of Alberta Hospital pathology laboratory, where gastric biopsies from our community projects were processed and assessed, enhances the validity of the distinct patterns observed in the Arctic communities.

\section{Conclusions}

We have offered an example of the value of communitydriven investigations for generating descriptions of the public health burden from diseases identified by affected communities and their healthcare providers to be of high community impact. This research provides evidence of a high burden of disease from $\mathrm{Hp}$ infection in Indigenous communities of western Arctic Canada. These results add to a small body of evidence that demonstrates the need for targeted interventions aimed at reducing health risks from $H p$ infection in Indigenous Arctic communities. In keeping with communityuniversity research agreements, all results have been disseminated within participating communities to address voiced concerns and support community efforts to advocate for relevant resources and policies. In addition, our collaborative team has used these disease burden results, along with results from treatment trials and longitudinal follow-up [17, 42], to create $H p$ clinical guidelines (not yet published) specific to healthcare practitioners serving Arctic communities in Canada.

\section{Abbreviations \\ CANHelp: Canadian North Helicobacter pylori; Cl: Confidence interval; H2RA: H2-receptor antagonist; Hp: Helicobacter pylori; MALT: Mucosa- associated lymphoid tissue; NT: Northwest Territories; PCR: Polymerase chain reaction; PPI: Proton pump inhibitor; RNA: Ribonucleic acid; UBT: 13C-urea breath test; YT: Yukon}

\section{Acknowledgements}

We thank the communities of Aklavik, Old Crow, Fort McPherson, and Tuktoyaktuk for their participation and contributions to this research. We acknowledge Taylor Cromarty for designing Fig. 1.

\section{Authors' contributions}

Each author reviewed the manuscript and gave final approval of the version to be published. Each author takes responsibility for the content that pertains to their area of expertise and agrees to ensure that questions about the accuracy or integrity of any part of the work are investigated and resolved. KFG created databases, cleaned, managed and analyzed data, constructed tables, and drafted the manuscript. JG led community project planning workshops, solicited community input as needed, contributed to the design of participant recruitment and data collection methods, directed 
data collection, created databases, and reviewed the manuscript critically for intellectual content. HJC contributed to the design of participant recruitment and data collection methods and created databases. LM led community project planning workshops, solicited community input as needed, contributed to the design of participant recruitment and data collection methods, and directed data collection. EW led community project planning workshops, solicited community input as needed, directed data collection, and presented results to community planning committees for review. ACol led community project planning workshops, solicited community input as needed, and directed data collection. SVZ directed endoscopy-based inquiry and contributed to planning clinical activities carried out in communities, designing diagnostic testing components, analyzing data and interpreting results. SG designed and directed histopathology-based inquiry and contributed to interpretation of results. BA led the engagement of community members in project planning and contributed to the design of participant recruitment and data collection methods. $\mathrm{BH}$ facilitated the input of Yukon health care providers in the research design and contributed to interpretation of results. ACor facilitated the input of Northwest Territories health care providers in the research design and contributed to interpretation of results. JM contributed to the design and implementation of clinical activities. RM facilitated community engagement in research planning and contributed to the design of participant recruitment and data collection methods. KJG led the collaborative team in designing the research, engaging collaborators, as well as analyzing and interpreting the data, and revised the manuscript critically for intellectual content. Other members of the CANHelp Working Group contributed to the design of research activities and instruments and interpretation of results.

\section{Funding}

This work was supported by grants from ArcticNet Network of Centres of Excellence of Canada; the Canadian Institutes for Health Research [MOP115031, IPH108285, 90386]; and Alberta Innovates Health Solutions [201201159]. KJG was supported by a Senior Health Scholar award from the Alberta Heritage Foundation for Medical Research. In-kind support for fieldwork came from Canadian North airlines and Olympus Canada. The funding bodies had no role in study design, data collection, data analysis, data interpretation, or in writing the manuscript.

\section{Availability of data and materials}

The datasets used for the current study are available from the corresponding author on reasonable request following community review of proposed data uses.

\section{Ethics approval and consent to participate}

This research was approved by the University of Alberta Health Research Ethics Board - Biomedical Panel (study ID Pro00007868). Written informed consent was obtained from all participants or their guardians.

\section{Consent for publication}

Not applicable.

\section{Competing interests}

The authors declare that they have no competing interests.

\section{Author details}

${ }^{1}$ Department of Medicine, Division of Gastroenterology, University of Alberta, Edmonton, Alberta, Canada. ${ }^{2}$ School of Public Health, University of Alberta, Edmonton, Alberta, Canada. ${ }^{3}$ Department of Laboratory Medicine and Pathology, University of Alberta, Edmonton, Alberta, Canada. ${ }^{4}$ Aklavik Health Committee, Aklavik, Northwest Territories, Canada. ${ }^{5}$ Government of Yukon, Whitehorse, Yukon, Canada. ${ }^{6}$ Government of the Northwest Territories, Yellowknife, Northwest Territories, Canada. ${ }^{7}$ Stanton Territorial Hospital, Yellowknife, Northwest Territories, Canada. ${ }^{8}$ Susie Husky Health Centre, Aklavik, Northwest Territories, Canada.
Received: 25 September 2018 Accepted: 29 May 2019

Published online: 11 June 2019

\section{References}

1. Goodman KJ, Jacobson K, van Zanten SV. Helicobacter pylori infection in Canadian and related Arctic aboriginal populations. Can J Gastroenterol. 2008:22:289-95.

2. Brown LM. Helicobacter pylori: epidemiology and routes of transmission. Epidemiol Rev. 2000;22:283-97.

3. Hooi JKY, Lai WY, Ng WK, Suen MMY, Underwood FE, Tanyingoh D, et al. Global prevalence of helicobacter pylori infection: systematic review and meta-analysis. Gastroenterology. 2017;153:420-9.

4. Peleteiro B, Bastos A, Ferro A, Lunet N. Prevalence of helicobacter pylori infection worldwide: a systematic review of studies with national coverage. Dig Dis Sci. 2014:59:1698-709.

5. Sugano K, Hiroi S, Yamaoka Y. Prevalence of helicobacter pylori infection in Asia: remembrance of things past? Gastroenterology. 2018;154:1257-8.

6. The EUROGAST Study Group. Epidemiology of, and risk factors for, Helicobacter pylori infection among 3194 asymptomatic subjects in 17 populations. The EUROGAST study group. Gut. 1993;34:1672-6.

7. Everhart JE, Kruszon-Moran D, Perez-Perez Gl, Tralka TS, McQuillan G. Seroprevalence and ethnic differences in helicobacter pylori infection among adults in the United States. J Infect Dis. 2000;181:1359-63.

8. Sinha SK, Martin B, Sargent M, McConnell JP, Bernstein CN. Age at acquisition of helicobacter pylori in a pediatric Canadian first nations population. Helicobacter. 2002;7:76-85.

9. CANHelp Working Group. www.canhelpworkinggroup.ca. Accessed 8 Jun 2018.

10. Cheung J, Goodman K, Munday R, Heavner K, Huntington J, Morse J, et al. Helicobacter pylori infection in Canada's arctic: searching for the solutions Can J Gastroenterol. 2008;22:912-6.

11. Carraher S, Chang H-J, Munday R, Goodman KJ. CANHelp working group. Helicobacter pylori incidence and re-infection in the Aklavik H. pylori project. Int J Circumpolar Health. 2013;72:21594.

12. Colquhoun A, Geary J, Goodman KJ. Challenges in conducting communitydriven research created by differing ways of talking and thinking about science: a researcher's perspective. Int J Circumpolar Health. 2013;72:21232.

13. Lefebvre M, Chang H-J, Morse A, van Zanten SV, Goodman KJ. CANHelp working group. Adherence and barriers to $\mathrm{H}$. pylori treatment in Arctic Canada. Int J Circumpolar Health. 2013;72:22791.

14. Cheung J, Goodman KJ, Girgis S, Bailey R, Morse J, Fedorak RN, et al. Disease manifestations of helicobacter pylori infection in Arctic Canada: using epidemiology to address community concerns. BMJ Open. 2014;4:e003689.

15. Hastings EV, Yasui Y, Hanington P, Goodman KJ. CANHelp working group. Community-driven research on environmental sources of $\mathrm{H}$. pylori infection in arctic Canada. Gut Microbes. 2014:5:606-17.

16. Kersulyte D, Bertoli MT, Tamma S, Keelan M, Munday R, Geary J, et al. Complete genome sequences of two helicobacter pylori strains from a Canadian Arctic aboriginal community. Genome Announc. 2015;3:e00209-15.

17. Morse AL, Goodman KJ, Munday R, Chang H-J, Morse JW, Keelan M, et al. A randomized controlled trial comparing sequential with triple therapy for helicobacter pylori in an aboriginal community in the Canadian north. Can J Gastroenterol. 2013;27:701-6.

18. Statistics Canada. Aklavik, HAM. 2006 Census of population. Ottawa; 2006.

19. Statistics Canada. Old Crow, Yukon (Code 6001043) and Yukon, Yukon (Code 6001) (table). Census Profile. 2011 Census. Ottawa; 2012.

20. Statistics Canada. Tuktoyaktuk, Northwest Territories (Code 6101036) and Canada (Code 01) (table). Census Profile. 2011 Census. Ottawa; 2012.

21. Statistics Canada. Fort McPherson, Northwest Territories (Code 6101015) and Canada (Code 01) (table). Census Profile. 2011 Census. Ottawa; 2012.

22. Statistics Canada. 2011 National Household Survey 2011.

23. Natural Resources Canada. Political map Northwest Territories. 2006. www nrcan.gc.ca/earth-sciences/geography/atlas-canada/reference-maps/16846. Accessed 8 Jun 2018.

24. Natural Resources Canada. Political map Yukon. 2006. www.nrcan.gc.ca/ earth-sciences/geography/atlas-canada/reference-maps/16846. Accessed 8 Jun 2018

25. Inuvialuit Regional Corporation. irc.inuvialuit.com. Accessed 8 Jun 2018.

26. Best LM, Takwoingi Y, Siddique S, Selladurai A, Gandhi A, Low B, et al. Noninvasive diagnostic tests for helicobacter pylori infection. Cochrane Database Syst Rev. 2018;3:CD012080. 
27. Gisbert JP, Pajares JM. Review article: 13C-urea breath test in the diagnosis of helicobacter pylori infection -- a critical review. Aliment Pharmacol Ther. 2004;20:1001-17.

28. Laine L, Lewin DN, Naritoku W, Cohen H. Prospective comparison of H\&E, Giemsa, and Genta stains for the diagnosis of helicobacter pylori. Gastrointest Endosc. 1997:45:463-7.

29. Lee JY, Kim N. Diagnosis of helicobacter pylori by invasive test: histology. Ann Transl Med. 2015;3. https://doi.org/10.3978/j.issn.2305-5839.2014.11.03.

30. Mégraud F, Lehours P. Helicobacter pylori detection and antimicrobial susceptibility testing. Clin Microbiol Rev. 2007;20:280-322.

31. Braden B, Haisch M, Duan LP, Lembcke B, Caspary WF, Hering P. Clinically feasible stable isotope technique at a reasonable price: analysis of 13CO2/ 12CO2-abundance in breath samples with a new isotope selectivenondispersive infrared spectrometer. Z Gastroenterol. 1994;32:675-8.

32. Koletzko S, Koletzko B, Haisch M, Hering P, Seeboth I, Hengels K, et al. Isotopeselective non-dispersive infrared spectrometry for detection of helicobacter pylori infection with 13C-urea breath test. Lancet. 1995;345:961-2.

33. Cheung J, Goodman K, Bailey R, Fedorak R, Morse J, Millan M, et al. A randomized trial of topical anesthesia comparing lidocaine versus lidocaine plus xylometazoline for unsedated transnasal upper gastrointestinal endoscopy. Can J Gastroenterol. 2010;24:317-21.

34. Dixon MF, Genta RM, Yardley JH, Correa P. Classification and grading of gastritis. The updated Sydney system. International workshop on the histopathology of gastritis, Houston 1994. Am J Surg Pathol. 1996;20:1161-81.

35. Blanchard TG, Nedrud JG. Laboratory maintenance of helicobacter species. Curr Protoc Microbiol. 2006:00(1):8B.1.1-8B.1.13.

36. Graham DY. History of helicobacter pylori, duodenal ulcer, gastric ulcer and gastric cancer. World J Gastroenterol. 2014;20:5191-204.

37. Hansson LE, Nyrén O, Hsing AW, Bergström R, Josefsson S, Chow WH, et al. The risk of stomach cancer in patients with gastric or duodenal ulcer disease. N Engl J Med. 1996;335:242-9.

38. Kawai K, Watanabe Y, Hayashi K. An epidemiological study of gastric to duodenal ulcer ratio in Asian countries. Gastroenterol Jpn. 1991;26:267-70.

39. Correa P, Piazuelo MB. The gastric precancerous cascade. J Dig Dis. 2012;13:2-9.

40. Nolen LD, Bruden D, Miernyk K, McMahon BJ, Sacco F, Varner W, et al. H. Pylori-associated pathologic findings among Alaska native patients. Int J Circumpolar Health. 2018;77:1510715.

41. Statistics Canada. Edmonton [Census metropolitan area], Alberta and Division No. 11, CDR [Census Division], Alberta (table). Census Profile. 2016 Census. Ottawa; 2017.

42. van Zanten SV, Girgis S, Munday R, Chang H-J, Fagan-Garcia K, Assi A, et al Su1215 - Gastric Pathology Follow-Up Study in Canadian Arctic Communities. Gastroenterology. 2018;154:S-505.

\section{Publisher's Note}

Springer Nature remains neutral with regard to jurisdictional claims in published maps and institutional affiliations.

Ready to submit your research? Choose BMC and benefit from:

- fast, convenient online submission

- thorough peer review by experienced researchers in your field

- rapid publication on acceptance

- support for research data, including large and complex data types

- gold Open Access which fosters wider collaboration and increased citations

- maximum visibility for your research: over $100 \mathrm{M}$ website views per year

At $\mathrm{BMC}$, research is always in progress.

Learn more biomedcentral.com/submissions 